\title{
CLINICAL FEATURES OF CHRONIC BRONCHITIS AND GENETIC RISK FACTORS FOR THE DEVELOPMENT OF CHRONIC OBSTRUCTIVE PULMONARY DISEASE IN ADOLESCENT SMOKERS
}

\author{
Svitlana Ilchenko ${ }^{1 *}$ and Anastasiia Fialkovska ${ }^{1}$
}

Author information: ${ }^{1}$ Department of Propedeutics of Pediatric Diseases, Dnipropetrovsk Medical Academy of the Ministry of Health of Ukraine; 9, Vernadsky St, Dnipro, 49044, Ukraine; e-mail: ilchensv@gmail.com.

\begin{abstract}
Introduction: Chronic bronchitis (CB) is a multifactorial disease with a complex number of internal and external etiological risk factors. One of the main risk factors for the development of $\mathrm{CB}$ in adolescents and chronic obstructive pulmonary disease (COPD) in adults is tobacco smoking. It is also known that an important internal risk factor for the development of $C B$ is a genetic predisposition.

Methods: We examined 40 adolescent smokers with $\mathrm{CB}, 30$ never-smoker adolescents with $\mathrm{CB}$, and 37 healthy adolescent smokers (control group). Each patient's history was collected along with findings from an objective examination. Molecular genetic investigations were conducted on 30 adolescent smokers with CB and 30 healthy adolescent smokers. Calculation of the smoking index and the packs/year were made.

Results: Smoking leads to the development of CB as early as adolescence and affects its course, increasing the frequency and duration of bronchitis attacks. We identified an association of the 2G/2G genotype of MMP1 gene with the development of CB in adolescent smokers. The TT genotype of CYP1A1 gene may be considered as a possible sustainability factor for the development of $\mathrm{CB}$ in adolescent smokers.

Conclusions: The study of candidate genes for COPD in childhood and adolescence will facilitate the early detection of high-risk groups in the formation of this pathology, which will allow doctors to take the necessary preventive measures.
\end{abstract}

Key words: chronic bronchitis, COPD, tobacco smoking, adolescents.

INTRODUCTION Chronic bronchitis (CB) in children and adolescents is a pressing problem in childhood pulmonology [1-3]. CB is a multifactorial disease with a complex etiology, involving a number of internal and external risk factors [4]. Tobacco-smoking is one of the main risk factors for the development of $\mathrm{CB}$ in adolescents and chronic obstructive pulmonary disease (COPD) in adults $[5,6]$. COPD is a leading cause of morbidity and mortality worldwide that includes substantial and increasing economic and social burdens. COPD is currently the fourth leading cause of death in the world but is projected to advance to the 3rd leading cause of death by 2020. More than 3 million people died of COPD in 2012, accounting for $6 \%$ of all deaths globally [6].

\footnotetext{
*Corresponding author: S. Ilchenko,

9, Vernadsky St.,Dnipro, 49044, Ukraine; e-mail: Ilchensv@gmail.com

phone +38 (050) 453-48-16

S. Ilchenko, A. Fialkovska @
}

Environmental exposures in childhood are important to the pathogenesis of COPD. Attenuation of lung growth due to air pollution in childhood is a risk factor for adult-onset respiratory disease. Common pulmonary cellular and molecular mechanisms underlying impaired innate host defenses in children exposed to air pollution and susceptibility to infection result in lung damage initiated in childhood that contributes to the global COPD health issue that is further exacerbated by exposure to tobacco smoke [7].

The clinical manifestations and the course of diseases of the broncho-pulmonary system are determined not only by the duration of harmful factors, but also by the individual characteristics of the person [8]. Therefore, genetic predisposition with regard to immunological reactivity and growth and development of the lungs are closely linked [8]. Today, the genetic mechanisms responsible for the formation of COPD in adults have become the object of large-scale research around the world [9-11], but in childhood, the genetic risk factors for chronic respiratory diseases, except for bronchial 
asthma and cystic fibrosis, have been largely ignored. Thus, the study of the role of tobacco smoking in the development of $\mathrm{CB}$ in children and adolescents with analysis of molecular genetic factors can provide additional information on the mechanisms of disease formation and will allow us to predict these conditions and develop methods for disease prevention.

The purpose of the study is to investigate the clinical features of the course of $\mathrm{CB}$ in adolescent smokers and to study the genetic risk factors for the development of COPD.

METHODS We examined 107 adolescents. Patients were divided into three groups. Group 1 consisted of 40 adolescent smokers with chronic bronchitis (mean age $17.5 \pm 0.2$ years). Group 2 consisted of 30 neversmokers adolescents with chronic bronchitis (mean age $16.0 \pm 0.4$ years). Group 3 (control group) consisted of 37 healthy adolescents-smokers (average age $16.3 \pm 0.3$ years). Diagnoses were verified based on standard criteria (laboratory-clinical and instrumental examination).

The study included each patient's account of his/her medical history and an objective examination. The status of smoking among adolescent smokers has been examined as a risk factor for the development of the disease with the calculation of the smoking index (SI), which was defined as the number of cigarettes smoked per day multiplied by years smoked. The indicator, pack/year, was also calculated as the number of cigarettes smoked per day/20 x number of years smoked.

To achieve our aim to study the genetic risk factors for the development of COPD, the MMP1 gene -1607 1G/2G (rs1799750) polymorphism and CYP1A1 gene T3801C polymorphism were studied. Molecular genetic investigations were performed at the Institute of Hereditary Pathology, Academy of Medical Sciences of Ukraine. The study material was DNA isolated from the peripheral blood leukocytes of 30 patients randomly selected from Group 1 and 30 patients randomly selected from Group 3. DNA was isolated from leukocytes and purified, using the kits for the GenePak DNA polymerase chain reaction (PCR) test (IzoGen Laboratory, Russia). The DNA sequences were amplified in vitro, using the PCR method and the restriction fragment length polymorphism method. The PCR was performed under an automatic regimen in a Tercik thermocycler (DNA Technology, Russia), using oligonucleotide primers (Fermentas, Lithuania), specific restriction endonucleases, and the GenPak PCR Core kits of agents for amplification (IzoGen Laboratory, Russia). The restriction fragments were analyzed and the specificity of PCR products were electrophoretically determined.

All statistical calculations were performed using Statistica v 10.0. Results were presented as means \pm standard deviation (SD), medians, and interquartile range (Q25; Q75). Each of the single nucleotide polymorphisms (SNPs) in genes of interest was analyzed for Hardy-Weinberg equilibrium using a computer program for analyzing genetic data (GeneExpert, http://gen-exp.ru/calculator_or.php). To determine the SNPs associated with the risk of $\mathrm{CB}$, the frequencies of the genotypes of the two study groups were compared, and the odds ratio (OR) was calculated with a 95\% confidence interval (Cl). Statistical significance was defined as $p<0.05$.

RESULTS The analysis of the tobacco smoking status (Table 1) showed that patients in Group 1 began smoking at the same age as the adolescent smoking controls (Group 3), but smoked significantly more cigarettes per day, had significantly higher values of $\mathrm{SI}$, and smoked more packs/year than the Group 3. Group 1 had also smoked more years, but the mean age in

\begin{tabular}{|c|c|c|c|}
\hline & Group 1 $(\mathrm{n}=40)$ & Control 3 $(\mathrm{n}=37)$ & $\mathrm{p}$ \\
\hline \multirow{2}{*}{ Age of the beginning of smoking, years } & 14.0 & 14.0 & $\mathrm{p}>0.05$ \\
& $(12.0 ; 14.0)$ & $(13.0 ; 15.0)$ & \\
\hline \multirow{2}{*}{ Years of active tobacco smoking } & 4.0 & 2.0 & $\mathrm{p}<0.05$ \\
\hline \multirow{2}{*}{ Number of cigarettes smoked per day } & $(3.0 ; 5.5)$ & $(1.0 ; 2.0)$ & $\mathrm{p}<0.05$ \\
\hline Smoking index & 10.0 & $(5.0 ; 10.0)$ & $\mathrm{p}<0.05$ \\
\hline \multirow{2}{*}{ packs/year } & $(10.0 ; 13.5)$ & 84.0 & \\
\hline
\end{tabular}

Table 1. Indicators of the tobacco smoking status in adolescent smokers, Medians (Q25; Q75) 


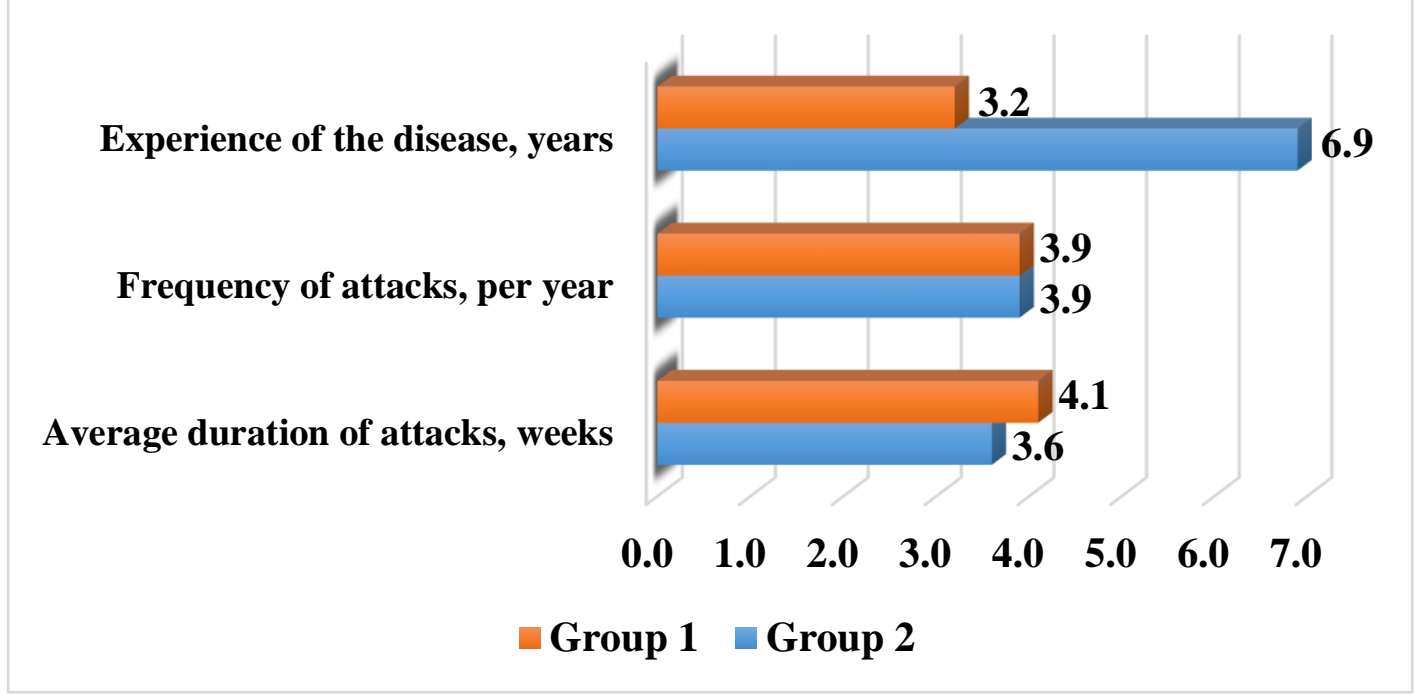

Figure 1. Clinical and anamnestic features of the course of chronic bronchitis in the examined adolescents

the group was also older.

A comparison of the clinical features of bronchitis showed that patients in Group 2 had bronchitis longer than those in Group $1(6.9 \pm 0.8$ vs. $3.2 \pm 0.2$ years, respectively; $\mathrm{p}<0.05$ ) (Figure 1 ). The number of bronchitis attacks per year among patients in Group 1 and Group 2 were similar ( $3.9 \pm 0.1$ vs. $3.9 \pm 0.3 ; p>0.05)$, but patients in Group 1 experienced longer durations of the attacks than patients in the non-smoking Group $2(4.1 \pm 0.1$ weeks versus $3.6 \pm 0.1$ weeks; $p<0.05)$.

Among the adolescent smokers of Group 1, the durations of the attacks differed, but the frequency of attacks correlated with the number of smoked cigarettes per day $(r=+0.56 ; p<0.05)$, SI $(r=+0.56$; $p<0.05)$ and the pack-year $(r=+0.59 ; p<0.05)$.

Analysis of clinical data showed that the course of $C B$ in adolescent smokers in the period of clinical remission was characterized by complaints of permanent $(65.0 \%$ vs $12.5 \% ; p<0.05)$ low-productive cough $(95.0 \%$ vs $18.7 \% ; p<0.001)$ predominantly in the mornings $(90.0 \%$ vs $25.0 \% ; p<0.001)$. Bronchitis attacks in patients of Group 1 compared to Group 2, were characterized by the absence of seasonality (90.0\% vs $25.0 \%$; $p<0.001)$, complaints of lowproductive cough $(80.0 \%$ vs $31.2 \% ; p<0.01)$ with predominantly mucosal sputum $(85.0 \%$ vs $25.0 \%$;

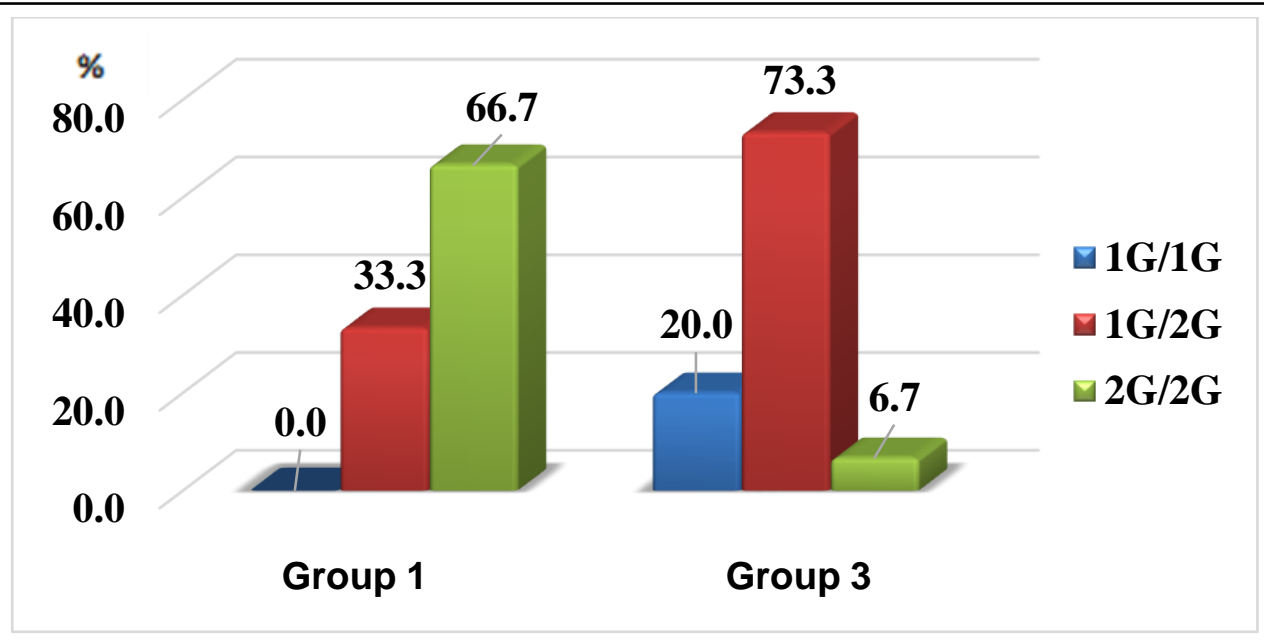

Figure 2. Genotype frequencies of MMP1 gene -1607 1G/2G (rs1799750) polymorphism in the studied groups. 
$p<0.001)$, dyspnea during exercise (60.0\% vs $25.0 \%$; $\mathrm{p}<0.05)$, and prevalence during auscultation of dry wheezing $(70.0 \%$ vs $6.3 \%$; $p<0.05)$. In Group 2, more patients were likely to exhibit moist rales $(56.2 \%$ versus $20.0 \% ; p<0.05)$ and mixed rales $(37.5 \%$ vs $10.0 \% ; \mathrm{p}<0.05$ ) at auscultation.

The results of the molecular genetic study revealed a statistically significant difference between Group 1 and Group 3 (Figure 2). When comparing the frequencies of the genotypes of the MMP1 gene -1607 1G/2G (rs1799750) polymorphism.

In patients of Group 1 compared with Group 3, the frequency of the homozygous genotype $2 \mathrm{G} / 2 \mathrm{G}$ was significantly higher $(66.7 \%$ vs $6.7 \% ; O R=28.00 ; 95 \% \mathrm{Cl}$ [2.82-277.97]). In the control group, the heterozygous genotype $1 \mathrm{G} / 2 \mathrm{G}$ was more common $(73.3 \%$ vs $33.3 \%$; $\mathrm{OR}=0.18 ; 95 \% \mathrm{Cl}[0.04-0.87])$.

The analysis of the frequency distribution of genotypes of the CYP1A1 gene showed a significant increase in the proportion of homozygous TT carriers in the control group compared to Group 1 (93.3\% vs $53.3 \%, \chi^{2}=6.21 ; p<0.05$ ) (Figure 3 ).

Thus, the molecular genetic study revealed the association of the 2G/2G genotype of MMP1 gene 1607 1G/2G (rs1799750) polymorphism (OR=28.00; $95 \% \mathrm{Cl}$ [2.82-277.97]) with the development of chronic bronchitis in adolescent smokers. The TT genotype of CYP1A1 gene T3801C polymorphism (OR=0.08; $95 \% \mathrm{Cl}[0.01-0.79]$ ) may be considered as a possible sustainability factor for the development of chronic bronchitis in adolescent smokers.
DISCUSSION The significance of tobacco use with $C B$ in pediatric practice has been the subject of discussion for many years. The role of tobacco smoking in the development of chronic respiratory pathology is widely studied in adults, but rarely in children and adolescents. Our study demonstrated that smoking leads to the development of $C B$ in adolescence and affects its course, increasing the frequency and duration of bronchitis attacks. In addition, we found that the frequency of attacks correlates with the number of cigarettes smoked per day, SI, and packs smoked per year.

Furthermore, we established, that the $2 \mathrm{G} / 2 \mathrm{G}$ genotype of MMP1 gene -1607 1G/2G (rs1799750) polymorphism can be considered as a risk factor for the development of $\mathrm{CB}$ in Ukrainian adolescent smokers. The homozygous version of the gene with a deletion of guanine $2 \mathrm{G}$ is known to have higher transcriptional activity than the heterozygous one [12].

This causes an increase in the enzymatic activity of MMP-1 in lung epithelial cells and disrupts the balance in the protease-antiprotease system. MMP-1 hypersecretion causes destruction of Type III collagen and leads to the formation of emphysema [13].

Enzymes of a xenobiotic biotransformation system play an important role in protecting the lungs from toxic products that are contained in tobacco smoke YP1A1 (Cytochrome P450, family 1 , subfamily A, polypeptide 1) bioactivates benzopyrene and polycyclic aromatic hydrocarbons, two important components of tobacco smoke. The T3801C

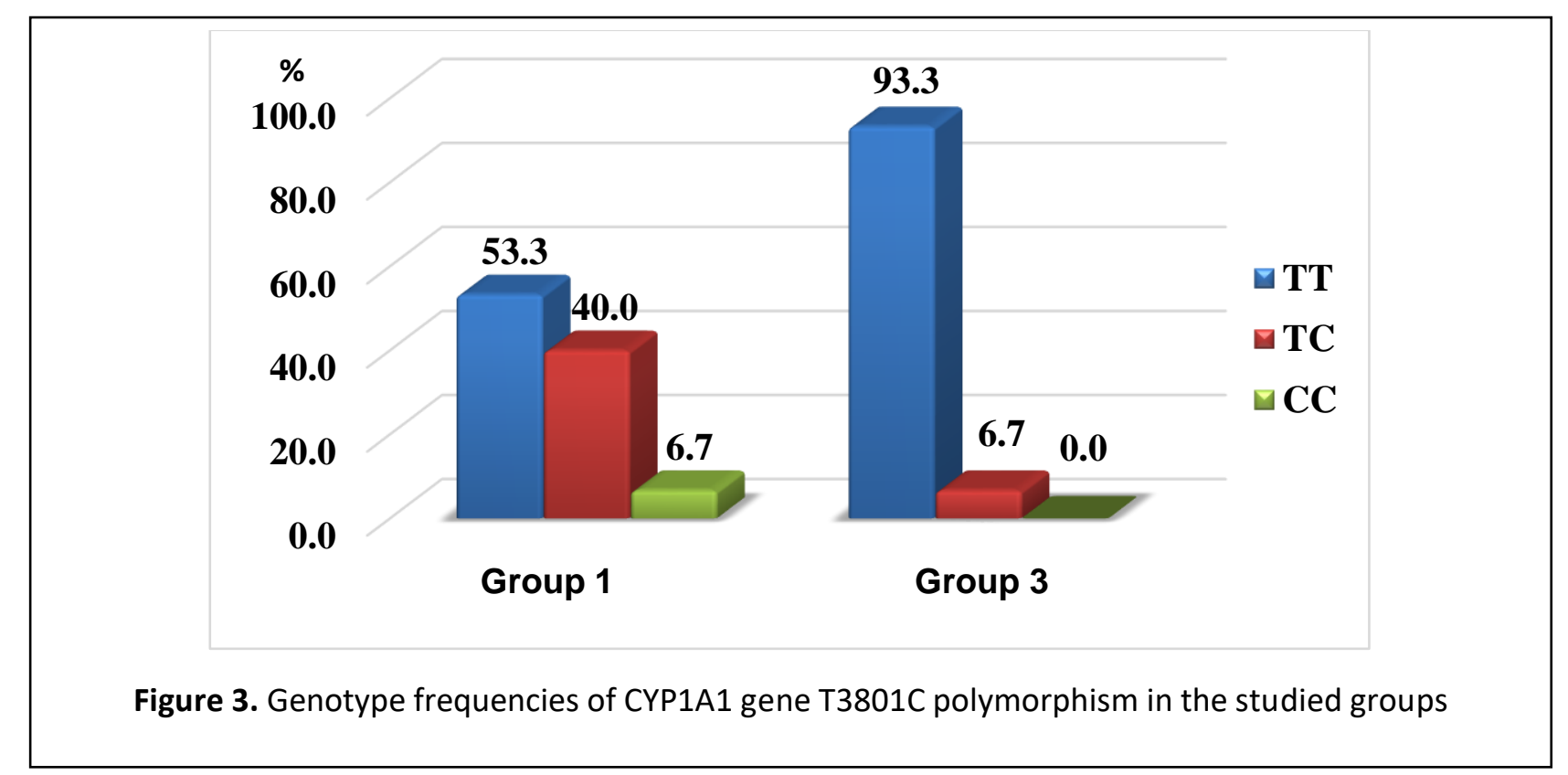


polymorphism of the CYP1A1 gene causes an amino acid replacement of thymine by cytosine, which leads to an increase in the enzymatic activity of the enzyme and the accumulation of active toxic substances in cells, including active oxygen molecules [14].

The active oxygen molecules have high cytotoxicity with respect to all cell types and contribute to the development of COPD. Damage to fibroblasts, reduction in the activity of surfactant, stimulation of the formation of thromboxane, increased epithelial permeability, and disruption of the function of cilia are increased [15]. The absence of mutation determines the normal level of synthesis and enzyme activity, which protects the lungs from toxic substances that are contained in tobacco smoke [16]. Thus, the presence of TT genotype of CYP1A1 gene T3801C polymorphism in adolescent smokers can be considered as a possible marker of resistance to chronic diseases of the respiratory system.

We have established that the development of CB in adolescents depends not only on the number of cigarettes smoked per day, $\mathrm{SI}$, and packs per year, but also on the presence of molecular genetic factors.

The study of the genes for COPD in childhood and adolescence will contribute to the early detection of high-risk patients for the development of this pathology, which may make it possible to encourage necessary preventive measures and to maximize postponement of disease development.

CONCLUSIONS Smoking leads to the development of $\mathrm{CB}$ as early as adolescence. The $2 \mathrm{G} / 2 \mathrm{G}$ genotype of MMP1 gene -1607 1G/2G (rs1799750) polymorphism can be considered as a risk factor for the development of $\mathrm{CB}$ in Ukrainian adolescent smokers, and the TT genotype of CYP1A1 gene T3801C polymorphism in adolescent smokers can be considered as a possible marker of resistance to $\mathrm{CB}$ of the respiratory system. The study of candidate genes for COPD in childhood and adolescence will facilitate the early detection of high-risk groups in development of $\mathrm{CB}$, which will allow doctors to take the necessary preventive measures.

\section{REFERENCES}

[1] Duka KD, Ilchenko SI, Shirikina MV. Peculiarities of the chronic bronchitis course among the children and adolescents in present conditions. Modern Pediatrics 2010; 2 (30): 77-8.
[2] Chang AB, Redding GJ, Everard ML. Chronic wet cough: Protracted bronchitis, chronic suppurative lung disease and bronchiectasis. Pediatr Pulmonol 2008; 43:519-31.

[3] Asilsoy S, Bayram E, Agin H, Apa H, Can D, Gulle $\mathrm{S}$, Altinoz $\mathrm{S}$. Evaluation of Chronic Cough in Children. Chest 2008; 134 (6): 1122-8. PMID:18689594, DOI: 10.1378/chest.08-0885.

[4] Duka KD, Ilchenko SI, Ivanus SG. Chronic bronchitis in children and adolescents - Past, Present and Future: Dnipropetrovsk, 2013.

[5] II'chenko SI, Cherginec' VI, Fialkovs'ka AO. Clinical and functional characteristics of chronic bronchitis in adolescents-smokers. Modern Pediatrics 2017; 3:112-6.

[6] GOLD 2017 Global Strategy for the Diagnosis, Management and Prevention of COPD. http://goldcopd.org/gold-2017-globalstrategy-diagnosis-management-preventioncopd/ (accessed Nov 19, 2018).

[7] Grigg J. Particulate Matter Exposure in Children Relevance to Chronic Obstructive Pulmonary Disease. ATS Journals 2009; 6 (7): 564-9. DOI: 10.1513/pats.200905-026RM.

[8] Probert K, Miller S, Kheirallah AK, Hall IP. Developmental genetics of the COPD lung. COPD. Research and Practice 2015:1-10. DOI: doi.org/10.1186/s40749-015-0014-x

[9] II'chenko SI, Fialkovskaia AA, Kramarenko NN, et al. The role of polymorphism of genes I and II phase of biotransformation of xenobiotics in the development of recurrent and chronic bronchitis in adolescents-smokers. Medical perspectives 2017; XXII (2): 85-90.

[10] Sotiriou I, Makris D. Genetic Implications in COPD. The Current Knowledge. Open Journal of Respir Diseases 2013; (3):52-62. DOI: 10.4236/ojrd.2013.32009

[11] Wu X, Yuan B, Lopez E. Gene polymorphisms and chronic obstructive pulmonary disease. J Cell Mol Med 2014; 18 (1): 15-26. PMC3916114 DOI: 10.1111/jcmm.12159.

[12] Dolinchuk LV, Basanets AV, Andrushchenko TA. Genetic aspects of chronic obstructive pulmonary disease development. Ukrainian J Prob Med Pract 2013; 1 (34): 44-56.

[13] Rohil V, Vijayan VK., Kumar R, et al. A study on the correlation of matrix metalloproteinase MMP1 in COPD and smoking in the North Indian population. Asian J Med Sci. 2017; 8 (1): 5-14. DOI: 10.3126/ajms.v8i1.1602.

[14] Soodaeva SK. Free radical mechanisms of injury in respiratory disease. Russian Pulmonol. 2012; 
(1): 5-10. DOI: doi.org/10.18093/0869-01892012-0-1-5-10

[15] Lemko OI. Some aspects of etiology, pathogenesis and duration of the chronic obstructive pulmonary disease (Part I). Scien Bulle Uzhhorod Univ. 2012; 1 (43): 180-189.
[16] Wang C-D, Nan C, Huang L, et al. Impact of CYP1A1 Polymorphisms on Susceptibility to Chronic Obstructive Pulmonary Disease: A Meta-Analysis. Biomed Res Int. 2015; 2015: 942958. DOI: 10.1155/2015/942958. 